BRUNO RODRIGUES DE SOUZA

\title{
Julgamento Antecipado Parcial de Mérito
}

Dissertação de Mestrado

Orientador: Professor Titular Doutor Cândido Rangel Dinamarco

UNIVERSidade de SÃo Paulo

FACULDADE DE DiREITo

São Paulo - SP

2018 

BRUNO RodRIGUES DE SOUZA

\section{Julgamento Antecipado Parcial de Mérito}

Dissertação apresentada à Banca Examinadora do Programa de Pós-Graduação em Direito, da Faculdade de Direito da Universidade de São Paulo, como exigência parcial para obtenção do título de Mestre em Direito, na área de concentração Direito Processual Civil, sob a orientação do Professor Titular Doutor Cândido Rangel Dinamarco.

\section{Universidade de São Paulo}

FACULDADE DE DIREITO

$$
\text { São Paulo - SP }
$$




\section{Souzn, Bruno Rodrigues de}

Julgamento antecipado parcial de mérito / Brumo Rodrigues de Souza

orientador Cândido Rangel Dinamarco - São Paulo, 2018 .

144

Dissertação (Mestrado - Programa de Pós-Graduação em Direito Processual) Faculdade de Direito, Universidade de Sáo Paulo, 2018.

1. Julgamento fracionado de ménito. 2. Sentenças parciais. 3. Coisa julgada gradual I. Rangel Dinamarco, Cándido, orient. II. Título. 
SouZA, Bruno Rodrigues de

Julgamento antecipado parcial de mérito

Dissertação apresentada à Faculdade de Direito da Universidade de São como exigência parcial para obtenção do título de Mestre em Direito.

Aprovado em:

Banca Examinadora

Orientador

Prof. Titular Cândido Rangel Dinamarco

Prof. Dr. Instituição:

Julgamento: Assinatura:

Prof. Dr Instituição:

Julgamento: Assinatura:

Prof. Dr. Instituição: Assinatura: 

Ao meu pai Joel Rodrigues de Souza. 



\section{Agradecimentos}

Impossível não começar esse agradecimento por ele: o Professor. Minha eterna gratidão não só pela oportunidade de cursar o mestrado, mas, sobretudo, pela generosidade, humildade e companheirismo. Suas lições acadêmicas e seu exemplo de vida foram (e são!) essenciais na minha formação pessoal e profissional.

Muito obrigado aos meus familiares, principalmente minha esposa MARIANA PrÉTOLA. Sem o apoio incondicional que recebi de vocês e a compreensão pelos momentos em que me ausentei, esse trabalho não teria acontecido.

Aos amigos de Escritório: BRUno VASCOncelos CARRILHO LOPES, Caroline Dal Poz Ezequiel, Daniel Menegassi Zotareli, Daniel Raichelis Degenszajn, João Antônio CÁnovas Bottazzo Ganacin, Júlia Prado Mascarenhas, Lia Carolina Batista Cintra e Oswaldo Daguano Junior, meu muito obrigado pela harmoniosa convivência diária e pelos constantes e ricos debates sobre essa ciência tão rica que é o processo civil. 



\section{RESUMO}

SouZA, Bruno Rodrigues de. Julgamento antecipado parcial de mérito. 2018. 144 páginas. Dissertação (Mestrado) - Faculdade de Direito, Universidade de São Paulo, São Paulo, 2018.

O presente trabalho se dedica ao estudo do julgamento antecipado parcial de mérito no direito brasileiro. Rompendo com o dogma da unicidade da sentença, o novo Código de Processo Civil, em seu art. 356, passou a permitir o fracionamento do julgamento do mérito. Na primeira parte do trabalho são estabelecidas as premissas conceituais que nortearão os demais capítulos, como o conceito de mérito e os contornos da relação jurídica processual. No segundo capítulo são analisadas as hipóteses em que se é possível fracionar o julgamento do mérito. Para tanto, é feito um estudo sobre as diferentes formações do objeto do processo, com destaque para a cumulação de pedidos, litisconsórcio e pluralidade de causas de pedir. O terceiro capítulo versa sobre o tratamento recursal dispensado à decisão que fraciona o julgamento de mérito, abordando as principais polêmicas sobre o assunto. No capítulo final são analisadas as principais questões envolvendo a execução da decisão interlocutória de mérito e a sua rescisão.

Palavras-chave: 1 . Processo civil; 2. Julgamento fracionado do mérito; 3. Coisa julgada gradual. 



\begin{abstract}
SouZA, Bruno Rodrigues de. Partial judgement of merit. 2018. 144 pages. Dissertation (Master) - Law School, University of São Paulo, São Paulo, 2018.

The present work focuses on the partial judgement of merit over the course of the hearing in Brazilian law. Breaking with the dogma of one unique sentence, the new civil procedure code (art. 356) enables the fragmentation of the judgment of merit. The first Chapter establishes the conceptual premises that will guide the other chapters, such as the concept of meritum causae and the outline of the procedural relationship. The second chapter, based on a study of the different forms of meritum causae (joinder of claims and of parties), analyses the hypotheses in which it is possible to fragment the judgment of merit. The third chapter covers the appeal system of the partial judgment of merit, addressing its main controversies. Lastly, the final chapter analyses the main issues involving the execution of the interlocutory order and its rescission.
\end{abstract}

Keywords: 1. Civil procedure; 2. Fragmented judgement of merit; 3. Gradual res judicata. 



\section{SUMÁRIO}

INTRODUÇÃO.

CAPÍTULO I - PREMISSAS . .11

1.1. - O dogma da unidade do julgamento de mérito

1.2. - O julgamento fracionado do mérito nas reformas processuais do Código de Processo Civil de 1973

1.3. - Breves considerações sobre o fracionamento do julgamento de mérito em ordenamentos

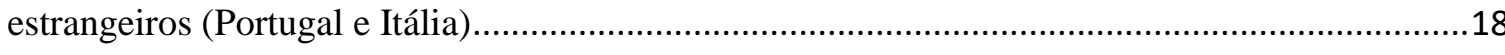

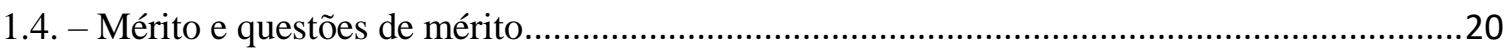

1.5. - Um breve parêntese: decisões interlocutórias de mérito (não sentenças parciais). ...............27

1.6. - Constitui dever ou faculdade do juiz solucionar a fração do mérito madura no curso do

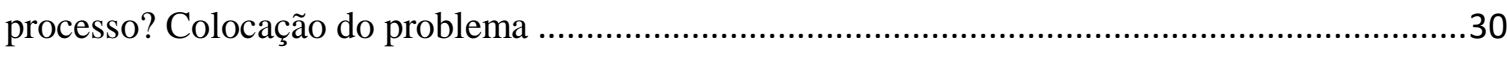

1.6.1. O juiz tem faculdades? A relação jurídica processual ....................................................31

1.6.2. A solução de fração do mérito no curso do processo é um dever: a promessa

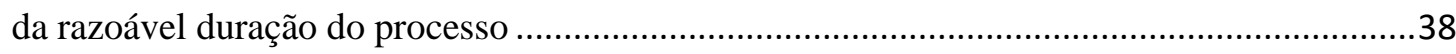

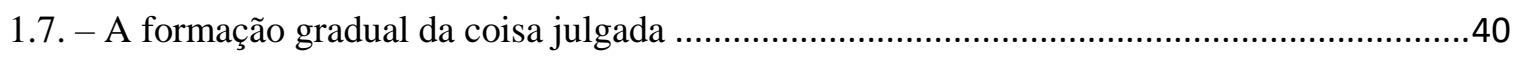

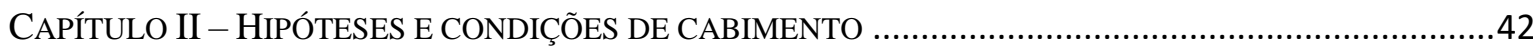

2.1. - Esclarecendo a expressão "pedido incontroverso": reconhecimento do pedido e renúncia do

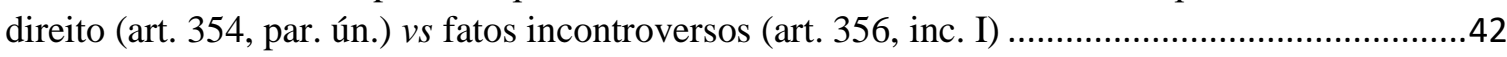

2.2. - Pedido em condições de julgamento imediato (art. 356, incs. I e II) ....................................47

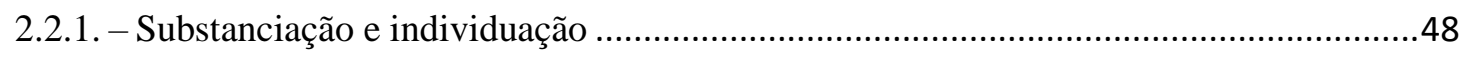

2.2.2. - A teoria adotada pelo sistema brasileiro ……........................................................... 50

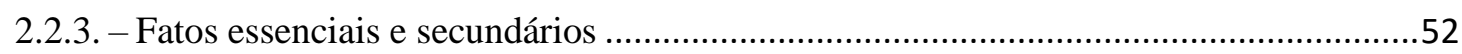

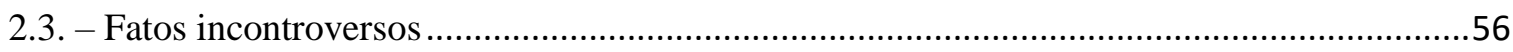

2.3.1. - Limitação da presunção de veracidade dos fatos incontroversos ..................................60

2.3.2. - Fatos incontroversos e a limitação instrutória do juiz ...................................................62

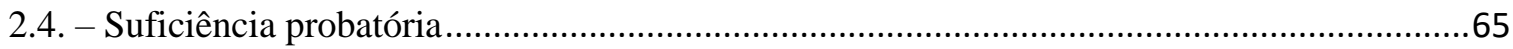

2.5. - Condições para o julgamento antecipado parcial do mérito - objeto do processo

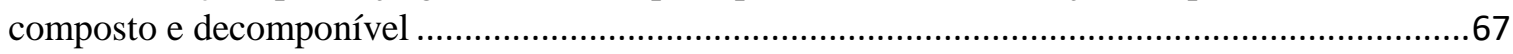

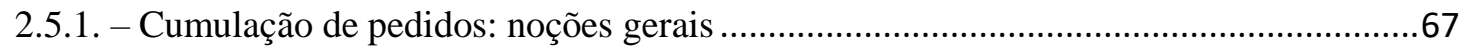

2.5.1.1. - Cumulação simples....................................................................................69

2.5.1.2. - Cumulação sucessiva ......................................................................................70

2.5.1.3. - Cumulação alternativa............................................................................... 72

2.5.1.4. - Cumulação eventual ou subsidiária ..............................................................74

2.5.2. - Litisconsórcio: noções gerais...................................................................................77 

2.5.2.1. - Litisconsórcio unitário .80

2.5.2.2. - Litisconsórcio comum (facultativo ou necessário) ..........................................81

2.5.2.3. - Litisconsórcio eventual, alternativo e sucessivo ...............................................84

2.5.3. - Cumulação de demandas em razão da pluralidade de causas de pedir ...........................86

2.6. - Julgamento liminar parcial de improcedência do mérito? .....................................................89

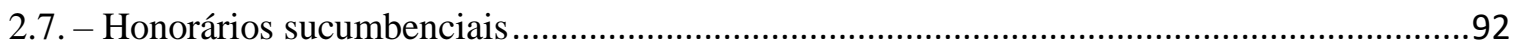

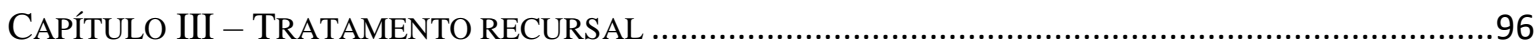

3.1. - Recurso cabível: fim de uma polêmica e início de várias outras ..........................................96

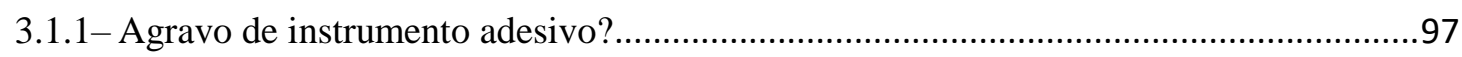

3.1.2. - É possível fazer sustentação oral na sessão de julgamento do agravo de instrumento?

3.1.3. - É possível aplicar a técnica do art. 942, caput, em sua integralidade, aos julgamentos dos agravos de instrumento interpostos contra decisões antecipadas e parciais de mérito?...102

3.1.4. - Efeito suspensivo 103

3.2. - Cabe recurso contra a decisão que indefere o pedido de uma das partes para que se proceda ao julgamento antecipado parcial de mérito? Uma possível saída de ordem prática. ...................107

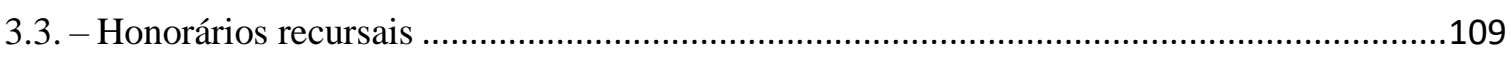

3.4. - Reexame necessário? Colocando o problema ...................................................................111

3.4.1 - Razão de ser do instituto ..................................................................................113

3.4.2. - Uma possível solução: a interlocutória de mérito está sujeita ao reexame necessário, mas sua eficácia não ficará suspensa até o reexame se completar.

CAPÍTULO IV - EXECUÇÃO, LIQUIDAÇÃO E RESCISÃO DA DECISÃO ANTECIPADA E PARCIAL DE

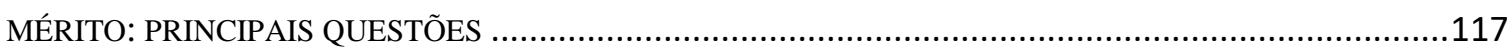

4.1. - Cumprimento provisório: o problema da desnecessidade de caução (CPC, art. 356, §2º 117

4.2. - Cumprimento definitivo contra a Fazenda Pública.........................................................122

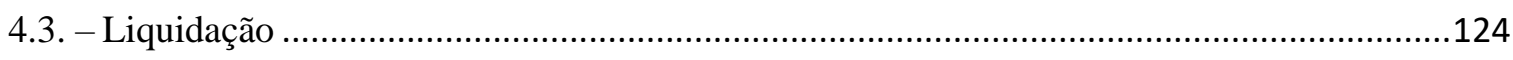

4.4. - Ação rescisória: início da contagem do prazo decadencial .............................................126

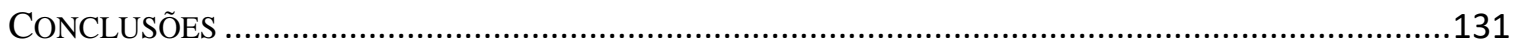

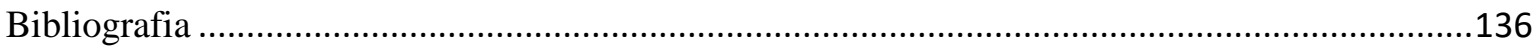





\section{INTRODUÇÃO}

"Que pena! O legislador não quis ousar mais, a ponto de autorizar (...) um parcial julgamento antecipado de mérito"1. Foram essas as palavras de CÂNDIDO RANGEL DinAMARCo para criticar a contenção do legislador em não instituir no sistema processual brasileiro a possibilidade de julgamento fracionado do mérito quando das reformas que alteraram o Código de Processo Civil de 1973. O novo Diploma Processual não pecou pela mesma falta de ousadia e, com os olhos voltados a oferecer prestação jurisdicional mais célere, sistematizou essa técnica de julgamento (art. 356).

Rompendo com o dogma da unidade do julgamento do mérito, o novo Código de Processo Civil, em homenagem ao princípio da celeridade processual e buscando racionalizar a tutela jurisdicional, estabeleceu a possibilidade de julgamento fracionado do mérito sempre que (a) inexistir controvérsia sobre "um ou mais dos pedidos formulados ou parcela deles" (art. 356, inc. I) ou ainda (b) quando algum dos pedidos "estiver em condições de imediato julgamento" (art. 356, inc. II). O raciocínio do legislador é muito lógico: se no curso do processo parcela do meritum causae estiver madura para julgamento, deverá o juiz, desde logo, solucioná-la, salvaguardando o jurisdicionado do dano marginal do processo. O lema do atual diploma processual é muito claro: a tutela jurisdicional deve ser outorgada da forma mais célere possível.

$\mathrm{O}$ tema julgamento antecipado parcial de mérito está longe de ser novidade no meio acadêmico. Sob a égide do Código de Processo Civil de 1973, parte da doutrina já defendia a possibilidade de cisão da análise do mérito no curso de qualquer processo de conhecimento. No entanto, ante a falta de norma expressa autorizando a aplicação dessa técnica e, por consequência, de uma disciplina sobre seus efeitos dentro do sistema processual, os debates doutrinários se concentravam na discussão sobre o cabimento do julgamento antecipado parcial de mérito. Relegados para segundo plano ficavam os demais institutos processuais afetados, com destaque para o recurso a ser manejado contra essa decisão interlocutória de mérito (agravo de instrumento? apelação por instrumento? apelação?).

Agora, com a cristalina autorização dada pelo art. 356, mostra-se relevante analisar a forma pela qual o novo Código de Processo Civil programou os efeitos da decisão parcial e antecipada de mérito. É justamente essa análise que constitui o objeto de estudo da presente dissertação de mestrado. Este trabalho buscará entender como o

\footnotetext{
${ }^{1}$ Dinamarco, Cândido Rangel. A reforma da reforma, 2aed. São Paulo: Malheiros, 2002, n. 50, p. 96.
} 
Código de Processo Civil operacionalizou o julgamento antecipado parcial de mérito, abordando (I) os pressupostos e condições para sua realização, (II) o tratamento recursal dispensado pelo Código e (III) os aspectos mais polêmicos envolvendo a execução da decisão interlocutória e sua rescisão. Para alcançar esses objetivos, no primeiro capítulo do trabalho serão fixadas as premissas conceituais que nortearão o desenvolvimento do estudo. 


\section{Conclusões}

Chegou o momento de sintetizar as principais conclusões alcançadas no curso deste trabalho. Para melhor exposição, isso será feito no formato de tópicos.

(I) Na incansável busca pela razoável duração do processo, a técnica de julgamento antecipado parcial do mérito veio mitigar o chamado dogma da unidade do julgamento de mérito. Com a atual permissão do art. 356, não há mais razões para se concentrar na sentença a análise do meritum causae. O referido dogma tem suas raízes plantadas na época em que se cultuava a oralidade no processo. Tendo sido superada essa forma de praticar os atos, não há mais razões para se manter essa concentração da análise do mérito na sentença.

(II) A permissão de cisão do julgamento do mérito no curso do processo, no entanto, não significa que o sistema passou a permitir a solução isolada das questões que o tocam. As questões de mérito somente poderão ser resolvidas quando houver efetiva solução do meritum causae.

(III) Para evitar equívocos no trato da decisão antecipada e parcial de mérito, é relevante abandonar a utilização da expressão "sentença parcial". O sistema processual criou uma disciplina própria para a decisão interlocutória de mérito, diferenciando-a, em muitos aspectos, da programada para a sentença, notadamente na esfera recursal. Em razão disso, o emprego correto da linguagem, com a abdicação da expressão "sentença parcial", evitará o manejo de expedientes processuais equivocados, algo que já é identificado no seio jurisprudencial.

(IV) O juiz não é dotado de discricionariedade no processo. Todos seus atos decorrem de um poder-dever a ele investido. Em função disso, sempre que for possível solucionar fração do meritum causae no curso do processo, constitui dever do órgão julgador se pronunciar a respeito. Essa é a única conclusão possível à luz da constitucional garantia da razoável duração do processo.

(v) Nos termos do art. 356, sempre que o pedido ou parcela dele estiver incontroverso ou maduro, deverá ocorrer o fracionamento do julgamento de mérito. A expressão "pedido incontroverso" utilizada pelo art. 356 não diz respeito aos casos em que há reconhecimento do pedido ou renúncia ao direito. Essas duas situações são tratadas por outro dispositivo, qual seja, o art. 354, parágrafo único. Ao se referir a pedido 
incontroverso, em realidade, o Código de Processo Civil está a tratar das situações em que não há controvérsia sobre fatos.

(VI) Não é a ausência de controvérsia sobre qualquer fato que permitirá a solução antecipada e parcial do mérito. Os fatos incontroversos precisam efetivamente integrar a causa de pedir. Fala-se aqui dos chamados fatos essenciais, isto é, aqueles que figuram como "pressuposto inafastável da existência do direito submetido à apreciação judicial" 370 .

(VII) Para identificação dos fatos essenciais, apresentou-se no decorrer do trabalho três técnicas diferentes. No entender deste trabalho, a terceira delas é a que melhor se adequa ao sistema processual pátrio por guardar relação com a teoria da substanciação e também por conferir maior amplitude aos limites objetivos da coisa julgada. Segundo esse método, a identificação dos fatos essenciais é feita com referência às fattispecie de todos os fundamentos jurídicos que poderiam permitir o acolhimento da demanda, não se restringindo, portanto, ao específico fundamento jurídico invocado pelo autor.

(VIII) A ausência de controvérsia fática pode ocorrer de duas formas: a) o réu não se desincumbe do ônus de impugnação específica (CPC, art. 341) ou b) concorda expressamente com os fatos alegados pelo autor (confissão). Em ambas situações, como não há divergência sobre os episódios da vida narrados no processo, o sistema processual presume-os verdadeiros, permitindo ao juiz que julgue a causa diretamente. Essa presunção, no entanto, é limitada em alguns casos. Segundo o art. 341, incs. I, II e III, não serão presumidos verdadeiros os fatos não impugnados em contestação quando: a) não for admissível a seu respeito a confissão, b) a petição inicial não estiver acompanhada de instrumento que a lei considerar substância do ato; e c) estiverem em contradição com a defesa, considerada em seu conjunto. Além disso, também não devem ser admitidos como verdadeiros os fatos improváveis, inverossímeis ou impossíveis. Nessas situações, o juiz está autorizado a seguir na instrução para apurar os fatos.

(IX) Para se permitir o julgamento de fração do meritum causae, é necessário também que o objeto do processo comporte cisão, isto é, ele deve ser composto ou decomponível. As diferentes formações litisconsorciais também limitarão a aplicação da técnica de julgamento antecipado e parcial do mérito. A mesma coisa ocorre nos casos em que há uma pluralidade de causas de pedir.

${ }^{370}$ CRUZ E TUCCI, A causa petendi no processo civil, n. 4.4.2, p. 163. 
(x) Aprofundando-se sobre os diferentes formatos do objeto do processo, analisou-se como o fracionamento do meritum causae se dá nas diferentes formas de cumulação de pedidos. Sendo simples a cumulação, não se identificam óbices para cisão do julgamento de mérito. Nessa modalidade os pedidos são independentes entre si, admitindo soluções heterogêneas. Na cumulação sucessiva, por existir uma relação de prejudicialidade entre os pedidos cumulados, o julgamento antecipado e parcial somente poderá ocorrer para acolher o pedido prejudicial. Sendo a cumulação alternativa, não há espaço para utilização da técnica de julgamento antecipado parcial. Nessa modalidade só um dos pedidos é analisado, impedindo, portanto a "descumulação". A cumulação eventual permite o julgamento antecipado parcial de mérito somente nas hipóteses em que o pedido principal for improcedente.

(XI) As diferentes formas de litisconsórcio também limitam a aplicação da técnica de julgamento fracionado do mérito. No litisconsórcio unitário é impossível cindir o mérito do processo para julgá-lo apenas em relação a um dos litisconsortes. No litisconsórcio comum, caracterizado por permitir soluções heterogêneas paras os litisconsortes, mostra-se plenamente possível a cisão do mérito no curso do processo. Nos litisconsórcios eventual, alternativo e sucessivo, a regra é a mesma para as cumulações de pedidos que carregam o mesmo nome. A exceção está no litisconsórcio alternativo. Em algumas situações, em razão da natureza do objeto do processo, será possível julgar o mérito apenas em relação a um dos litisconsortes. Foi dado o exemplo da demanda de investigação de paternidade ajuizada contra dois homens que mantiveram relações sexuais com a mãe em datas próximas. Como só é possível ter um pai biológico, se no curso do processo ficar demonstrado que um dos réus não poderia ser o pai, como ocorre no caso de esterilidade, nada impede que haja o julgamento de mérito em relação a ele, seguindo o processo apenas em relação ao outro litisconsorte.

(XII) A pluralidade de causas de pedir também permite a cisão do julgamento do mérito. Foi demonstrado que "a existência de um concurso de causas de pedir relativas à mesma pretensão dá ensejo à propositura de tantas demandas quanto forem as causas de pedir" ${ }^{371}$. Em razão disso, se no curso do processo uma dessas causas de pedir estiver suficientemente instruída, poderá o juiz julgar improcedente o mérito com base nela, seguindo a instrução em relação aos demais fundamentos. Obviamente que se

${ }^{371}$ BRUNO VASCONCELOS CARRILHO LOPES, Limites objetivos e eficácia preclusiva da coisa julgada, n. 8, p. 50. 
com base nessa causa de pedir se entender que a demanda é procedente, será proferida sentença solucionando todo o meritum causae.

(XIII) Concluiu-se no item 2.6 que é plenamente possível se proceder ao julgamento liminar parcial de improcedência do mérito. Apesar de não haver norma expressa, a garantia da razoável duração do processo e o princípio da economia processual autorizam essa hipótese.

(XIV) Buscou-se também solucionar uma controvérsia hoje existente no meio jurisprudencial: o arbitramento de honorários advocatícios pela decisão que fraciona o julgamento do mérito. Ora, ao solucionar parte do meritum causae, define-se quem deu causa àquela fração do objeto do processo, elemento que permite a imposição da verba sucumbencial. Como sobre essa decisão forma-se coisa julgada e, portanto, não é possível alterá-la, não há motivos para não impor desde já a condenação ao pagamento de honorários sucumbenciais.

(XV) No terceiro capítulo foram analisadas as principais controvérsias no âmbito recursal. Como a decisão que fraciona o julgamento do mérito é interlocutória, impugnável, portanto, por agravo de instrumento, ela segue um caminho diferente do previsto para a sentença. O tratamento diferenciado causa estranheza pois ambos os pronunciamentos têm o mesmo conteúdo e valor. Dentre essas diferenças foram ressaltadas as seguintes: a) cabe agravo de instrumento adesivo? É possível fazer sustentação oral quando do julgamento do agravo de instrumento interposto contra a decisão interlocutória de mérito? Deve ser aplicada em sua plenitude a técnica do art. 942 quando houver divergência no julgamento do agravo de instrumento? Demonstrou-se que o elemento chave para responder a tais indagações está na identificação de eventuais ofensas a garantias constitucionais. Com esse fundamento, chegou-se a conclusão que: a) não cabe agravo de instrumento adesivo, pois nessa hipótese não há cerceamento do duplo grau de jurisdição; b) é possível fazer sustentação oral, pois ela constitui importante ferramenta da ampla defesa, sendo sua limitação uma ofensa constitucional; e, por fim, c) não é possível aplicar a técnica do art. 942 em sua plenitude.

(XVI) Foi analisado se a decisão interlocutória de mérito estaria sujeita ao reexame necessário. A conclusão alcançada buscou um meio termo: tal decisão está sujeita sim ao reexame necessário, no entanto, em razão de sua eficácia imediata, seus efeitos não ficarão contidos até a finalização do reexame pela instância superior. 
(XVII) No último capítulo do trabalho foram estudadas as principais questões envolvendo o cumprimento e a liquidação da decisão parcial e antecipada de mérito. No que diz respeito ao cumprimento provisório, concluiu-se que a parte pode tomar tal iniciativa independentemente de caução, no entanto, a prática de atos expropriatórios exige essa garantia, a exemplo do que estabelece o art. 520, inc. IV.

(XVIII) No último capítulo chegou-se à conclusão de que, sendo definitiva a execução da decisão interlocutória de mérito contra a Fazenda Pública, nada impede a imediata expedição de precatório ou requisição de pequeno valor. Não há transgressão da regra contida no art. $100, \S 8^{\circ}$, da Constituição Federal.

(XIX) Por fim, foi analisada a data em que é iniciada a contagem do prazo decadência para ajuizamento da ação rescisória que tenha por objeto decisão parcial e antecipada de mérito. Após estudar as diferentes opiniões sobre o assunto, chegou-se a conclusão de que a decisão interlocutória de mérito pode transitar em julgado antes da sentença, no entanto, o prazo para ajuizamento da ação rescisória somente passa a fluir quando a sentença passar em julgado. Isso, no entanto, não impede que se afore ação rescisória antes de se alcançar tal marco temporal. O raciocínio é análogo ao contido no art. $218, \S 4^{\circ}$, que considera tempestivo "o ato praticado antes do termo inicial do prazo". 


\section{BIBLIOGRAFIA}

ABDo, Helena Najjar. O abuso do processo, São Paulo: Revista dos Tribunais, 2007.

AlCAlÁ-Zamora Y CASTILlo. Niceto. Proceso, autocomposición y autodefensa: contribucíon al estúdio de los fines del processo. Cidade do México: UNAM, 2000.

AmBrizzI, Tiago Ravazzi. Julgamento fracionado do mérito no processo civil brasileiro. Dissertação (mestrado em Direito Processual) - Faculdade de Direito da Universidade de São Paulo. São Paulo: 2014.

AraúJo, José Aurélio de. Cognição sumária, cognição exaustiva e coisa julgada. São Paulo: Revista dos Tribunais, 2017.

Assis, Araken de. Cumulação de ações, 4ªed. São Paulo: Revista dos Tribunais, 2002. . Manual dos recursos, $8^{\mathrm{a}}$ ed. São Paulo: Revista dos Tribunais, 2016. . Processo civil brasileiro, vol. I, $2^{\mathrm{a}}$ ed. São Paulo: Revista dos Tribunais, 2016. . Processo civil brasileiro, vol. II, t. I. São Paulo: Revista dos Tribunais, 2015. . Processo civil brasileiro, vol. II, t. II. São Paulo: Revista dos Tribunais, 2015.

Assis, Arnoldo Camanho de. Fungibilidade recursal e sustentação oral: um caso concreto. Disponível em: https://www.academia.edu/34997927/FUNGIBILIDADE_RECURSAL_E _SUSTENTA\%C3\%87\%C3\%830_ORAL_UM_CASO_CONCRETO

BARBOSA, Bruno Valentim. Julgamentos parciais de mérito no processo civil individual brasileiro. Dissertação (mestrado em Direito Processual) - Faculdade de Direito da Universidade de São Paulo. São Paulo: 2013.

BArbosa Moreira, José Carlos. O processo civil brasileiro e o procedimento por audiências, in Temas de direito processual: sexta série. São Paulo: Saraiva, 1997.

2013.

. Comentários ao código de processo civil, vol. V, 17a ed. Rio de Janeiro: Forense,

. O novo processo civil brasileiro, $28^{\mathrm{a}}$ ed. Rio de Janeiro: Forense, 2010.

. Correlação entre o pedido e a sentença, in Revista de Processo, vol. 83, jul./set. 1996.

O futuro da justiça: alguns mitos, in Temas de Direito Processual Civil ( $8^{a}$ série).

São Paulo: Saraiva, 1984. 
. O problema da divisão do trabalho entre juiz e partes: aspectos terminológicos, in Revista de Processo, vol. 41/1986.

A conexão de causas como pressuposto da reconvenção. São Paulo: Saraiva, 1979.

. Litisconsórcio unitário. Rio de Janeiro: Forense, 1972.

. Em defesa da revisão obrigatória das sentenças contrárias à Fazenda Pública, in Revista do Instituto de Pesquisas e Estudos, Bauru, n. 44, set./dez. 2005.

Bedaque, José Roberto dos Santos. Poderes instrutórios do juiz, 5 a ed. São Paulo: Revista dos Tribunais, 2011

Bondiol, Luiz Guilherme Aidar. O Novo CPC: a terceira etapa da reforma. São Paulo: Saraiva, 2006. $\overline{\mathrm{jul} / 2016 .}$

Procedimento comum: fase postulatória, in Revista dos Tribunais, vol. 257/2016, . Comentários ao Código de Processo Civil, vol. XX. São Paulo: Saraiva, 2016.

BoNício, Marcelo José Magalhães. Notas sobre a tutela antecipada 'parcial' na nova reforma do Código de Processo Civil, in Revista dos Tribunais, vol. 808, fev. 2003.

Bove, Mauro. "Sentenza non definitive e riserva d'impugnazione", in Rivista Trimestrale di Diritto e Procedura Civile, Milão, Giuffrè, 1998.

Brasil. Código de processo civil. Código de processo civil: histórico da lei. Brasília: Senado Federal, Subsecretaria de Edições Técnicas, 1974.

Bueno, Cássio Scarpinella. Tutela antecipada, 2ªed. São Paulo: Saraiva, 2007. 2007. . A nota etapa da reforma do código de processo civil, v. 2. São Paulo: Saraiva,

BURIL, Macêdo de Lucas. Improcedência liminar do pedido, in Revista dos Tribunais, vol. 973/2016.

Calamandrei, Piero. Opere giuridiche, v. $4^{\circ}$. Napoli: Morano, 1970.

Calmon de Passos, José Joaquim. Comentários ao Código de Processo Civil, vol. III. Rio de Janeiro: Forense, 1991.

CAmardi, Giuseppe. Le Sentenze non Definitive su Questioni Preliminari di Merito. Tese de Doutorado. Universitá di Bologna, 2008. 
CAnova, Augusto Cerino. "La domanda giudiziale e il suo contenuto", in Commentario del codice di procedura civile, T. 1. Torino: UTET, 1980.

. "Sul contenuto delle sentenze non definitive di merito", in Rivista di Diritto Processuale, 1971.

CARmona, Carlos Alberto. Em torno da petição inicial, in Revista de processo, vol. $119 / 2005$.

CARneIRo, Athos Gusmão. Da antecipação de Tutela, $5^{\mathrm{a} e d . ~ R i o ~ d e ~ J a n e i r o: ~ F o r e n s e, ~} 2004$.

CARnelutTI, Francesco. Instituicones del processo civil, v. I, $5^{\mathrm{a} e d}$., trad. SANTIAGo Sentis MELENDO. Buenos Aires: Ediciones jurídicas Europa-America, 1989.

CARPI, Federico; Colesanti, Vittorio; TARUfFo, Michele. Commentario breve al codice di procedura civile. Padova: Cedam, 2002.

Carvalho, Milton Paulo de. Do pedido no processo civil. Porto Alegre: Sérgio-FabrisFIEO, 1992.

ChIOvenda, Giuseppe. Principios de derecho procesal civil, trad. JosÉ CASAIS Y SANTALÓ, t. I. Madrid: Reus, 1922.

CINTRA, Lia Carolina Batista. Intervenção de terceiro por ordem do juiz: a intervenção iussu iudicis no processo civil. São Paulo: Revista dos Tribunais, 2017.

Costa, Moacyr Lobo da. Confissão e reconhecimento do pedido, in Revista da Faculdade de Direito, v. 62.

Couture, Eduardo Juan. Fundamentos del derecho procesal civil, $3^{\mathrm{a} e d}$. Buenos Aires: Depalma, 1958.

CRuZ E Tucci, José Rogério. A causa petendi no processo civil, $3^{\mathrm{a}}$ ed. São Paulo: Revista dos Tribunais, 2009.

. Reflexões sobre a cumulação subsidiária de pedidos, in BEDAQUE, José Roberto dos Santos; TuCCI, José Rogério Cruz e (Coords.). Causa de pedir e pedido no processo civil: questões polêmicas. São Paulo: Revista dos Tribunais, 2002.

. Comentários ao código de processo civil, v. VII. São Paulo: 2016, Saraiva.

- Tempo e processo: uma análise empírica das repercussões do tempo na fenomenologia processual (civil e penal). São Paulo: Revista dos Tribunais, 1997.

Cunha, Leonardo Carneiro. A Fazenda Pública em Juízo, 14ªed. Rio de Janeiro: Forense, 2017. 
. O $\S 6^{\circ}$ do art. 273: tutela antecipada parcial ou julgamento antecipado parcial da lide?, in Revista Dialética de Direito Processual, nº 1. São Paulo, 2003.

Daguano Junior, Oswaldo. A litispendência no processo civil. Dissertação (mestrado em Direito Processual) - Faculdade de Direito da Universidade de São Paulo. São Paulo: 2016.

Dantas, Bruno. Comentários ao código de processo civil, vol. 4, Bueno, Cássio Scarpinella (coord.). São Paulo: Saraiva, 2017.

DIDIER JunIOR, Fredie. Curso de direito processual civil, 17 a ed. Salvador: Juspodivm, 2015

Inovações na antecipação dos efeitos da tutela e resolução parcial do mérito, in. Revista de processo, vol. 110/2003.

Dinamarco, Cândido Rangel. Instituições de Direito Processual Civil, v. I. $8^{\text {a ed. São }}$ Paulo: Malheiros, 2016.

_ Instituições de Direito Processual Civil, v. II. 7ªed. São Paulo: Malheiros, 2017.

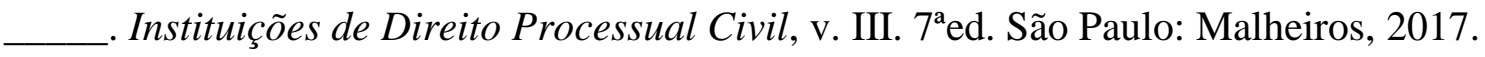

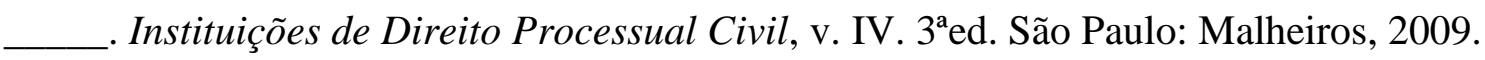

. A Reforma da Reforma. 2aed. São Paulo: Malheiros, 2002.

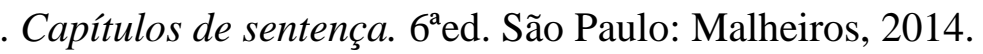

- O conceito de mérito em processo civil, in Fundamentos do processo civil moderno, t. I, $6^{\text {a }}$ ed. São Paulo: Malheiros, 2010.

. Fundamentos do processo civil moderno, t. II, 6ª ed. São Paulo: Malheiros, 2010.

_Litisconsórcio, $7^{\mathrm{a}}$ ed. São Paulo: Malheiros, 2002.

. A arbitragem na teoria geral do processo. São Paulo: Malheiros, 2013.

. Execução civil, $7^{\mathrm{a}}$ ed. São Paulo: Malheiros, 2000.

. Nova era do processo civil, $4^{\mathrm{a}}$ ed. São Paulo: Malheiros, 2013.

. Vocabulário do processo civil. São Paulo: Malheiros, 2009. 
Donoso, Denise. Julgamento prévio do mérito: análise do art. 285-A do CPC. São Paulo: Saraiva, 2011.

DuARTE, Ronnie Preuss. Litisconsórcios alternativo e subsidiário no processo civil brasileiro, in Revista de Processo, vol. 147/2007.

FonseCA, João Francisco Naves da. Comentários ao Código de Processo Civil, vol. IX. São Paulo: Saraiva, 2017.

Frederico Marques, José. Manual de Direito Processual Civil, vol. II. $2^{\text {a }}$ ed. São Paulo: Saraiva, 1976.

GAJARDONI, Fernando da Fonseca. O princípio constitucional da tutela jurisdicional sem dilações indevidas e o julgamento antecipadíssimo da lide, in Revista de Processo, vol. $141 / 2006$.

GiAnesini, Rita. A Fazenda Pública e o reexame necessário, in Aspectos polêmicos e atuais dos recursos cíveis, Vol. IV. São Paulo: Revistas dos Tribunais, 2001.

Giannico, Maurício. A preclusão no direito processual civil brasileiro. São Paulo: Saraiva, 2007.

GoldSCHIMIDT, James. Principios generales del processo, t. I. Buenos Aires: EJEA, 1961. . Derecho procesal civil, trad. Leonardo Prieto Castro. Barcelona: Labor, 1936.

GonÇAlves FILHO, João Gilberto. O princípio constitucional da eficiência no processo civil. Tese (doutorado em Direito Processual) - Faculdade de Direito da Universidade de São Paulo. São Paulo: 2010.

Grau, Eros. Por que tenho medo dos juízes, $6^{\mathrm{a}}$ ed., $2^{\mathrm{a}}$ tiragem. São Paulo: Malheiros, 2014.

Greco, Leonardo. Instituições de Processo Civil, vol. I. 5aed. Rio de Janeiro: Forense, 2015.

. Instituições de Processo Civil, vol. II. 3ªd. Rio de Janeiro: Forense, 2015.

. Instituições de Processo Civil, vol. III. Rio de Janeiro: Forense, 2015.

. Concurso e cumulação de ações, in Revista de Processo, v. 147/2007.

HeINITZ, Ernesto. I limiti oggettivi dela cosa giudicata. Padova: Cedam, 1937.

HouAISS, Antônio. Dicionário Houaiss da língua portuguesa. Rio de Janeiro: Objetiva, 2001. 
JARDIM, Augusto Tanger A causa de pedir no direito processual civil. Porto Alegre: Livraria do Advogado, 2008.

JORGE, Flávio Cheim. Teoria geral dos recursos cíveis, $7^{\mathrm{a} o}$ ed. São Paulo: Revista dos Tribunais, 2015.

LeITE, Clarisse Frechiani Lara. Prejudicialidade no Processo Civil. São Paulo: Saraiva, 2008.

Evicção e processo. São Paulo: Saraiva, 2013.

LEONEL, Ricardo de Barros. “A causa petendi nas ações coletivas”, in CRUZ E TUCCI, José Rogério; Bedaque, José Roberto dos Santos (coord.). Causa de pedir e pedido no processo civil: questões polêmicas. São Paulo: Revista dos Tribunais, 2002.

LIEBMAN, Enrico Tullio. Eficácia e autoridade da sentença e outros escritos sobre a coisa julgada, $4^{\mathrm{a}}$ ed. São Rio de Janeiro: Forense, 2007.

_. Problemi del processo civile. Milão: Morano, 1962.

. Appunti sulle impugnazioni. Milão: La Goliardica, 1961.

. Manuale di diritto procesuale civile, vol. II. Milão: Giuffrè, 1968.

LOPES, Bruno Vasconcelos Carrilho. Limites objetivos e eficácia preclusiva da coisa julgada. São Paulo: Saraiva, 2012. p. 297.

Comentários ao código de processo civil, vol. II. São Paulo: Saraiva, 2017, n. 232,

LuCCA, Rodrigo Ramina de. Julgamentos antecipados do mérito. In Revista de Processo, vol. 257, jul/16.

LuCON, Paulo Henrique dos Santos. Tutela provisória e julgamento parcial no CPC de 2015: avanços e perspectivas, in Novo Código de Processo Civil: questões controvertidas. São Paulo: Atlas, 2015.

MARINONI, Luiz Guilherme. Tutela antecipatória, julgamento antecipado e execução imediata da sentença, $3^{\text {a }}$ ed. São Paulo: revista dos Tribunais, 1999.

Precedentes obrigatórios. São Paulo: Revista dos Tribunais, 2010.

Maximiliano, Carlos. Hermenêutica e aplicação do direito, $12^{\mathrm{a}} \mathrm{ed}$. Rio de Janeiro: Forense, 1992 
MAZZEI, Rodrigo. Litisconsórcio sucessivo: breves considerações (pode ser acessado em http://www.mmp.adv.br/artigos/Litisconsorcio_Sucessivo.pdf)

MenESTRINA, Francesco. La prejudiciale nel processo civile. Viena: Manz, 1904.

Mesquita, José Ignacio Botelho de. Teses, estudos e pareceres de processo civil, v. 1. São Paulo: Revista dos Tribunais, 2005.

MirandA, Pedro de Oliveira. Novíssimo sistema recursal conforme o CPC/2015. Florianópolis: Conceito Editorial, 2015, p. 142.

MiRAndA, Vicente. Poderes do juiz no processo civil brasileiro. São Paulo: Saraiva, 1993.

MitidiERo, Daniel. Direito fundamental ao julgamento definitivo da parcela incontroversa: uma proposta de compreensão do art. $273, \S 6^{\circ}$, do CPC, na perspectiva do direito fundamental a um processo sem dilações indevidas (art. 5², LXXVII, da CF/1988), in Revista de Processo, n. 149, jul. 2007.

MoliCA, Rogério. Questões controvertidas sobre a remessa necessária no novo Código de Processo Civil, in ARAúso, José Henrique Mouta; CunHA, Leonardo Carneiro da; Rodrigues, Marco Antonio (Coords). Fazenda Pública, 2ed. Salvador: JusPodivm, 2016.

Monnerat, Fábio Victor da Fonte. Primeiras aplicações do art. 285-A do CPC, in Revista de Processo, vol. 157/2008.

MontesAnO, Luigi, "Questioni preliminar di merito", in Rivista Processuale, ano XXIV, jan-mar 1969.

Nery Junior, Nelson. Princípios do processo na constituição federal, 10. ${ }^{a}$ ed. São Paulo: Revista dos Tribunais, 2010.

Neto, Abilio. Código de Processo Civil anotado, 5aed. Lisboa: Petrony, 1983.

Neves, Daniel Amorim Assumpção. Manual de direito processual civil, vol. único, $8^{\mathrm{a}} \mathrm{ed}$. São Paulo: JusPodivm, 2016. 476-477.

Novo Código de Processo Civil - Lei 13.105/2015. São Paulo: Método, 2015, pp.

OliveIRA, Bruno Silveira de. Um novo conceito de sentença?, in Revista de Processo, vol. 149/2007. . Conexidade e efetividade processual. São Paulo: Revista dos Tribunais, 2007.

PIETRO, Maria Sylvia Zanella di. Direito administrativo, 14ªed. São Paulo: Atlas, 2002. 
PINTO, Junior Alexandre Moreira. A causa petendi e o contraditório. São Paulo: Revista dos Tribunais, 2007.

RASElli, Alessandro. Studi sul potere discrezionale del giudice civile. Milão: Giuffrè, 1975.

RECASÈns SicheS, Luís. Tratado general de filosofia del derecho, 9ªed. México: Porrúa, 1986.

ReIS, Alberto dos. Código de Processo Civil anotado, v. III. Coimbra: Editora Coimbra, 1950.

RICCI, Gian Franco. "Individuazone o sostanziazione nella reforma del processo civile", in Rivista trimestrale di diritto e procedura civile, 1995.

RizzI, Sérgio. Recurso adesivo, in Revista de processo, vol. 30/1983.

SÁNCHEZ, Guilherme Ormazabal. "Iura novit cúria: la vinculación del juez a la calificación jurídica de la demanda". Madrid: Marcial Pons, 2007.

SAnt'Anna, Paulo Afonso de Souza. Sentença parcial, in Revista de Processo, vol. 151/2007, set/2007.

SAntos, Andrés de la Oliva. Objeto del processo y cosa juzgada en el processo civil. Madrid: Thomson-Civitas, 2005.

SAntos, Moacyr Amaral. Primeiras Linhas de Direito Processual Civil, vol. $2^{\circ}, 16^{\text {a ed. São }}$ Paulo: Saraiva, 1994.

SAntos, Silas Silvas. Litisconsórcio eventual, alternativo e sucessivo. São Paulo: Atlas, 2013.

SicA, Heitor Vitor Mendonça. Preclusão processual civil, 2aed. São Paulo: Atlas, 2008.

. Algumas implicações do novo conceito de sentença no processo civil, de acordo com a lei n. 11.232/2005, n: CARMONA, Carlos Alberto (coord.). Reflexões sobre a reforma do Código de Processo Civil: estudos em homenagem à Ada Pellegrini Grinover, Cândido Rangel Dinamarco e Kazuo Watanabe. São Paulo: Atlas, 2007.

Silva, Ovídio Baptista da. Curso de processo civil, v. 1, 6ªed. São Paulo: Revista dos Tribunais, 2002.

Silva, Ricardo Alexandre da. Comentários aos arts. 355 e 356 do NCPC, in WAMBIER, Teresa Arruda Alvim; DIDIER JUNIOR, Fredie; TALAMINI, Eduardo; DANTAS, Bruno (Coord.). Breves comentário ao Novo Código de Processo Civil. São Paulo: Revista dos Tribunais, 2015. 
SIQUEIRA, Thiago Ferreira. O julgamento antecipado parcial do mérito no novo Código de Processo Civil brasileiro. Civil Procedure Review, v. 7, n. 1, jan-abr/2016.

SouZa Junior, Sidney Pereira de. Sentenças parciais no processo civil: consequências no âmbito recursal. São Paulo: Método, 2010.

Talamini, Eduardo. Comentário ao Código de Processo Civil, vol. 2, Bueno, Cassio Sarpinella (coord). São Paulo: Saraiva, 2017.

TARUfFO, Michelle. A motivação da sentença civil, trad. MitidiERO, Daniel. São Paulo: Marcial Pons, 2015.

. "Verità negoziata?", Rivista Trimestrale di Diritto e Procedura Civile - Numero speciale: Accordi di parte e processo, Milano, 2008.

WAMBIER, Luiz Rodrigues; TALAMINI, Eduardo. Curso avançado de processo civil, vol. 2, 16ªd. São Paulo: Revista dos Tribunais, 2016.

W AmBIER, Teresa Arruda Alvim. Nulidades do processo e da sentença, $5^{\mathrm{a} e d . ~ S a ̃ o ~ P a u l o: ~}$ Revista dos Tribunais, 2004.

WAMBIER, Teresa Arruda Alvim; DidiER Junior, Fredie; TAlamini, Eduardo; DAnTAS, Bruno (coords.). Breves comentários ao novo código de processo civil. São Paulo: Revista dos Tribunais, 2015.

WAMBIER, Teresa Arruda Alvim; ConCEIÇÃO, Maria Lúcia Lins; RIBEIRO, Leonardo Ferres da Silva; Mello, Rogério Licastro Torres de. Primeiros comentários ao novo código de processo civil. São Paulo: Revista dos Tribunais, 2015.

Watanabe, Kazuo. Da cognição no processo civil, $3^{\mathrm{a} e d}$. São Paulo: Perfil, 2005.

YARSHELL, Flávio Luiz. Breves notas sobre a disciplina da ação rescisória no CPC 2015, in O novo código de processo civil: questões controvertidas. São Paulo: Atlas, 2015.

Zavascki, Teori Albino. Antecipação da Tutela, 4ª ed. São Paulo, Saraiva, 2005. 